\title{
Microscopy of the Spinel-Forming Reaction with Nanoparticles
}

\author{
J.P. Winterstein, ${ }^{* * *}$, M. Sezen, ${ }^{* *}$ A. Rečnik*** and C.B. Carter* \\ * Department of Chemical, Materials \& Biomolecular Engineering, University of Connecticut, \\ Storrs, CT 06269 \\ ** Research Institute for Electron Microscopy and Center for Electron Microscopy Graz \\ (FELMI/ZFE), Graz University of Technology, A-8010 Graz, Austria \\ ***Department for Nanostructured Materials, Jožef Stefan Institute, 1000 Ljubljana, Slovenia.
}

A novel experimental setup for studying the initial stages of formation and growth of $\mathrm{MgAl}_{2} \mathrm{O}_{4}$ spinel on an $\alpha-\mathrm{Al}_{2} \mathrm{O}_{3}$ substrate has been devised. Nanometer-scale cubes of $\mathrm{MgO}$ formed by $\mathrm{Mg}$ combustion were deposited on (0001)-oriented single crystals of alumina by holding the specimen near burning $\mathrm{Mg}$ metal. Some of the $\mathrm{Al}_{2} \mathrm{O}_{3}$ was pre-thinned to electron transparency and annealed to remove the specimen preparation damage before depositing $\mathrm{MgO}$ particles; while cross-section specimens were prepared by focused ion beam from bulk specimens. Spinel-forming reactions were carried out in a furnace at temperatures from 1000 to $1100{ }^{\circ} \mathrm{C}$. Our experiments were designed to acquire some insights into how selection of surfaces and temperatures influence the interaction of oxide nanoparticles with substrates, a scenario applicable for a number of technologies.

TEM studies were performed on a FEI Tecnai 12 and a JEOL 2010F. Several tendencies in the alignment between the spinel and the $\mathrm{Al}_{2} \mathrm{O}_{3}$ can be identified from the microscopy and diffraction results. Orientation relationships depend on reaction time and temperature. Under epitaxial growth conditions, the spinel prefers an orientation with the $\mathrm{Al}_{2} \mathrm{O}_{3}$ such that the $\{111\}$ spinel planes are aligned parallel to the $(0001)$ of the $\mathrm{Al}_{2} \mathrm{O}_{3}$, with the $\langle 1 \overline{1} 0\rangle$ spinel direction parallel to the $\langle 10 \overline{1} 0\rangle$ of corundum. In some cases, however, the spinel orientation is imposed by the initial orientation of the $\mathrm{MgO}$ nanoparticles on basal surface of $\alpha-\mathrm{Al}_{2} \mathrm{O}_{3}$ substrate into an enforced cube-to-base orientation, where $\{001\}$ of hexahedral $\mathrm{MgO}$ sit parallel to (0001) of the $\mathrm{Al}_{2} \mathrm{O}_{3}$ and the spinel simply adopts the $\mathrm{MgO}$ orientation, i.e. $\{001\} \|(0001)$ relation [1]. SEM and TEM images show that the spinel particles are often faceted and protrude deep into the $\mathrm{Al}_{2} \mathrm{O}_{3}$ substrate as seen in figure 1. Both cross-section and plan-view specimens show stacking faults in some spinel particles and from the cross-section specimens, at least in the observed cases, the stacking faults in spinel lie on $\{1 \overline{1} 0\}$ and perpendicular to the original $\mathrm{MgO} / \mathrm{Al}_{2} \mathrm{O}_{3}$ interface as seen in figure 2. (111) sp $\mid(0001)_{\text {cor }}$ interface and the SFs can be observed edge-on along the $\langle\overline{1} 10\rangle_{\text {sp }}||\langle 10 \overline{1} 0\rangle_{\text {cor }}$.

HRTEM analysis of $\mathrm{MgAl}_{2} \mathrm{O}_{4} / \alpha-\mathrm{Al}_{2} \mathrm{O}_{3}$ cross-sections revealed that the interfaces are not atomically flat on the nominal composition $(111)_{\mathrm{sp}} \|(0001)_{\text {cor }}$ planes, but facet to other low-index lattice planes of both crystals. In addition there is a considerable strain in the spinel lattice due to in-plane lattice mismatch of $4.36 \%$ for $(1 \overline{1} 0)_{\text {sp }}$ vs. $(01 \overline{1} 0)_{\text {cor }}$ and $3.88 \%$ for $(11 \overline{2})_{\text {sp }}$ vs. $(2 \overline{1} \overline{1} 0)_{\text {cor }}$ (expressed relative to the oxygen sublattice constants of both structures at room temperature). Most of this strain appears to be relaxed into the epitaxial spinel layer. Due to these constraints it is difficult to find an unstrained interfacial section with the nominal $(111)_{\text {sp }} \|(0001)_{\text {cor }}$ interface, which limits the interpretability of the interfacial structure. Some oxygen columns nearly align across the interface. Comparison of images with simulations, however, permits analysis of the translation of the crystals across the interface. HRTEM analysis of typical $\mathrm{MgAl}_{2} \mathrm{O}_{4} / \alpha-\mathrm{Al}_{2} \mathrm{O}_{3}$ interface with orientational relationship and translation between the two crystals is illustrated in figure 3 [2]. 
References

[1] J.P. Winterstein and C.B. Carter, Microsc. Microanal., 15 (Suppl. 2) (2009) 1332.

[2] JPW is supported by the US and Austrian governments through a Fulbright grant. The authors would like to thank Martina Dienstleder for some of the FIB specimen preparation.
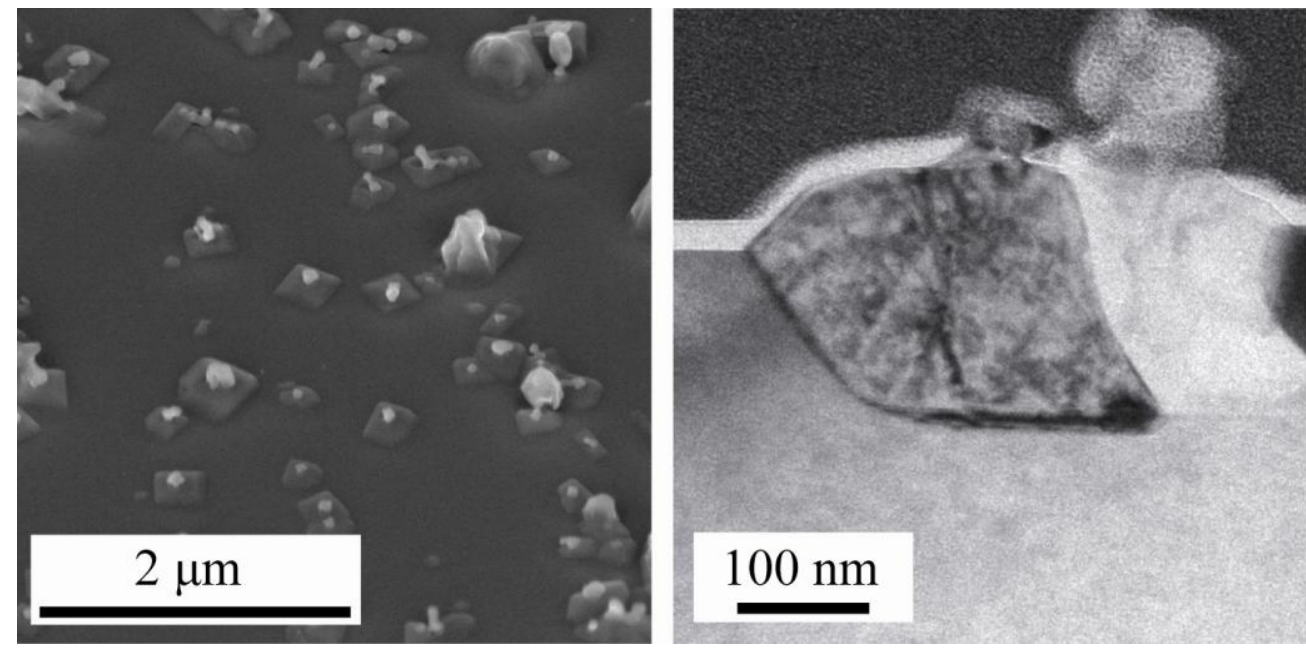

FIG 1. SEM (secondary electron) image (right) of an $\alpha-\mathrm{Al}_{2} \mathrm{O}_{3}$ bulk specimen with faceted spinel particles protruding from the surface with small amounts of remaining $\mathrm{MgO}$; TEM BF image (left) of a cross-section specimen showing the extent of spinel growth into the $\mathrm{Al}_{2} \mathrm{O}_{3}$. In the TEM image, several particles have impinged on each other. Both images were taken from the same specimen which was reacted at $1100{ }^{\circ} \mathrm{C}$ for 1 hour.

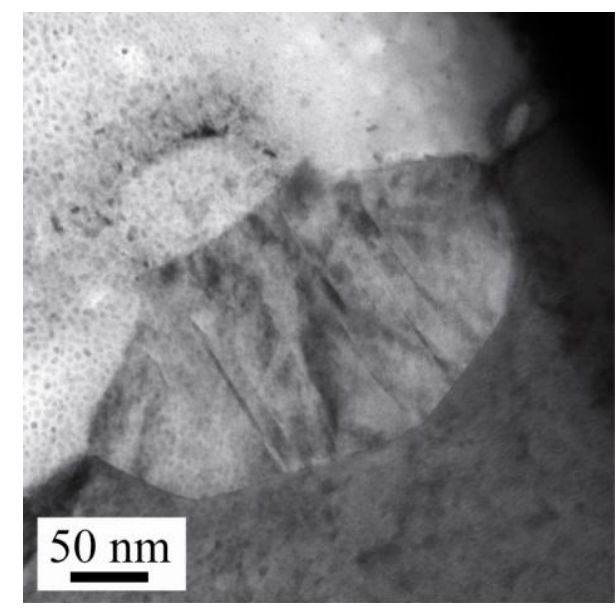

FIG 2. TEM BF image of a spinel particle growing into $\mathrm{Al}_{2} \mathrm{O}_{3}$ showing stacking faults running through the particle.
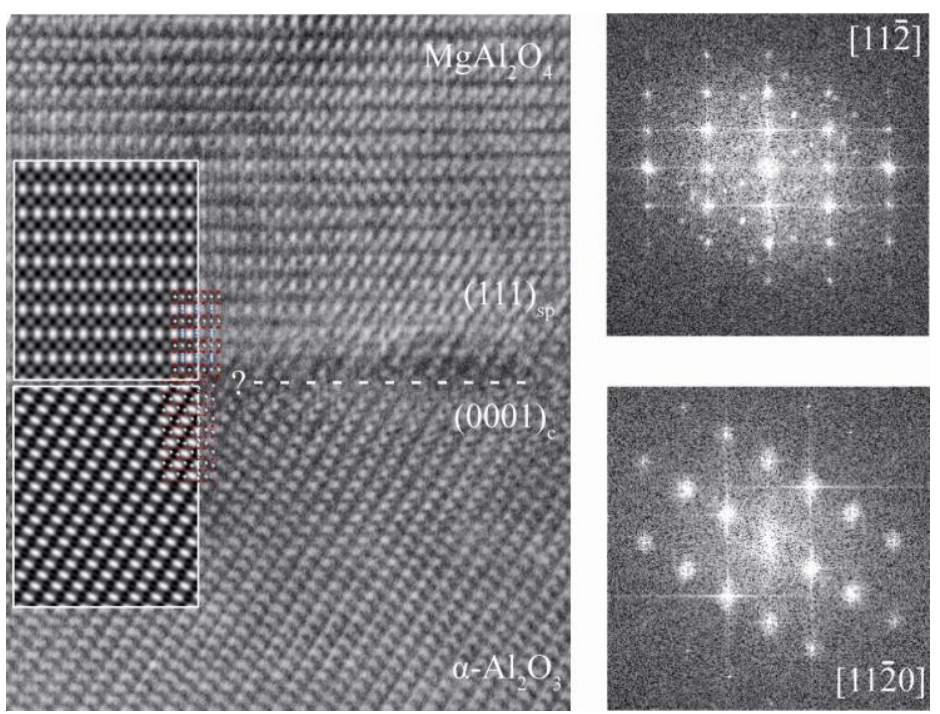

FIG 3. HRTEM image of an interface between spinel and $\mathrm{Al}_{2} \mathrm{O}_{3}$. The inset shows simulated images and the projected structures of the two phases. 